\title{
Influence of pH and Salt Concentration on the Helix-Coil Transition of Poly A Determined by a Modified DSC
}

\author{
Yoshihiro Baba, Shigeyuki TANaka, and Akihiro Kagemoto \\ Department of General Education, Osaka Institute of Technology, \\ Omiya-Asahi-ku, Osaka, 535 Japan.
}

(Received June 9, 1975)

\begin{abstract}
The thermal effects of $\mathrm{pH}$ and salt concentration on the helix-coil transition of Poly A were studied calorimetrically by a modified differential scanning calorimeter (DSC). The transition temperature $\left(\boldsymbol{T}_{\mathrm{m}}\right)$ and enthalpy $(\Delta H)$ of Poly $\mathrm{A}$ in acid solution depend both on $\mathrm{pH}$ and on the concentration of NaCl. $T_{\mathrm{m}}$ and $\Delta H$ increase with decreasing $\mathrm{pH}$ at infinite dilution of salt concentration, and decrease with increasing salt concentration at a definite $\mathrm{pH}$. These results indicate that electrostatic interactions between the negatively charged phosphate group and the positively charged adenine group contribute significantly with decreasing $\mathrm{pH}$.
\end{abstract}

KEY WORDS DSC / Poly A / Helix-Coil Transition / Transition Temperature / Transition Enthalpy / Dependence on $\mathrm{pH}$ and Concentration of $\mathrm{NaCl} /$

\section{INTRODUCTION}

Poly(riboadenylic acid) (Poly A) forms a double-strand helical structure in acid solutions, ${ }^{1}$ and this structure undergoes a transition to a random coil with increasing temperature. ${ }^{2}$ It has been reported from circular dichroism ${ }^{3}$ and hypochromism $^{4}$ that double-strand structure of Poly A is not stable, but a single-strand helical structure stabilized by base stacking exists at neutral $\mathrm{pH}$.

The helix-coil transition temperature of Poly $\mathrm{A}$ in acid solution is sensitive to the salt concentration $^{2,5}$ and to the $\mathrm{pH}^{6}$ It increases with decreasing $\mathrm{pH}$, and its dependence on salt concentration is the reverse of that in the DNA system, ${ }^{7,8}$ since it decreases with increasing salt concentration. It is also reported that the transition enthalpy of Poly $\mathrm{A}$, as well as the transition temperature, depends on $\mathrm{pH}^{9}$ But the dependence of the transition enthalpy of Poly A on salt concentration has not yet been measured using calorimetry.

In order to study the effect of $\mathrm{pH}$ and salt concentration upon the transition, the thermal stability of the double-strand helical structure of Poly A in acid solutions with various concentrations of $\mathrm{NaCl}$ has been studied by calorimetry; the enthalpy and the characteristic temperature of the helix-coil transition of Poly $A$ are the important parameters in understanding the stability of such molecules with doublestrand helical structures.

\section{EXPERIMENTAL}

\section{Materials}

Poly(riboadenylic acid) (Poly A) was purchased from Miles Co Ltd. (control No. 11-76-301) and was used without further purification. All other materials were commercial preparations of analytical reagent grade. $0.1-\mathrm{mol}$ acetate buffer solution was prepared to obtain the definite $\mathrm{pH}$ values for the experiment.

The Poly A sample was dissolved into the buffer solution with different $\mathrm{NaCl}$ concentrations by raising the temperature and then the Poly $\mathrm{A}$ solution obtained was allowed to stand overnight at about $278 \mathrm{~K}$.

For the calorimetric measurements the Poly A concentration was about $0.3 \%$, as determined by the measurement of absorption spectra at $252 \mathrm{~nm}$ taking $E(P)=10100$ at this wavelength, ${ }^{10}$ and the quantity of the Poly A solution used was about $30 \mu l$.

\section{Apparatus}

The modified differential scanning calorimeter (DSC) was the same as that in a previous paper. ${ }^{11}$ 
The optical rotation measurement was made using a spectropolarimeter (Japan Spectroscopic Co. Ltd., J-20). Water from a thermostat was circulated through the cell holder. The relation between both temperature and equilibrium cell temperature was established by a series of calibration experiments.

\section{RESULTS AND DISCUSSION}

The helix-coil transition of Poly $\mathrm{A}$ in acid solution with different concentrations of $\mathrm{NaCl}$ was studied by using a modified DSC. The heating rate was about $10 \mathrm{~K} / \mathrm{min}$. A typical DSC curve obtained for the concentration of Poly A of about $0.3 \%$ (the quantity of Poly A was about $50 \mu \mathrm{g}$ and the concentration of $\mathrm{NaCl}$ at $\mathrm{pH} 4.73$ was $10^{-3} \mathrm{~mol}$ ) is shown in Figure 1. The temperature width of the endothermic peak of the DSC curve, which ranges from about 343 to $353 \mathrm{~K}$, is about $10 \mathrm{~K}$. The maximum peak temperature of the thermal absorption is about $347 \mathrm{~K}$.

In order to confirm the results of the DSC method, we have measured the optical rotatory dispersion (ORD) in the same system. In Figure 1, the optical rotations per mean nucleotide residue $([R])$ at wavelength $282 \mathrm{~nm}$ are plotted against the temperature for the Poly A solution with $10^{-3}-\mathrm{mol} \mathrm{NaCl}$ at $\mathrm{pH} 4.73$. The helix-coil transition temperature $\left(T_{\mathrm{m}}\right)$ of Poly $\mathrm{A}$ is about $345 \mathrm{~K}$. The agreement between the transition temperature estimated from the

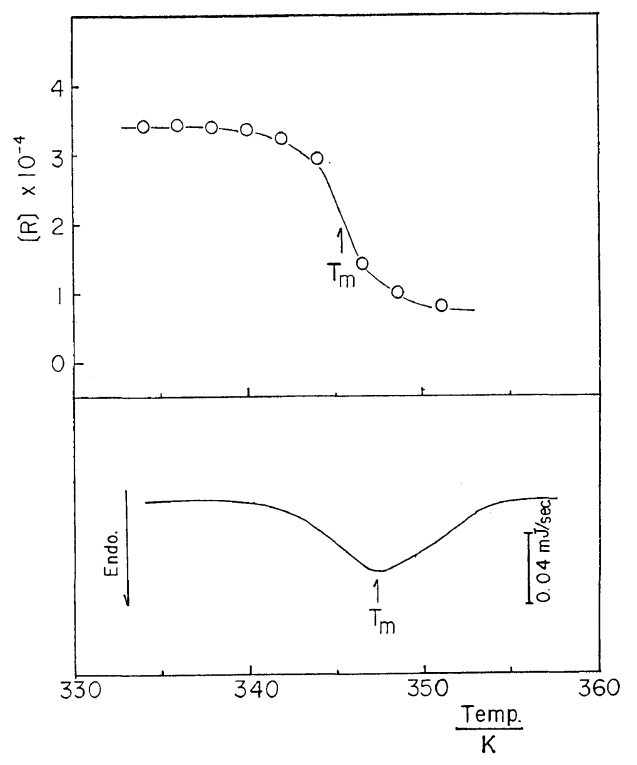

Figure 1. DSC curve and the temperature dependence of the optical rotation per mean nucleotides residue ([R]) at $282 \mathrm{~nm}$ for Poly A solution with $10^{-3} \mathrm{~mol} \mathrm{NaCl}$ in $\mathrm{PH} 4.32(0.1 \mathrm{M}$ acetate buffer solution): $T_{\mathrm{m}}$, transition temperature.

ORD method and peak temperature of the DSC curve is fairly close. Hence, the endothermic peak of the DSC curve may be regarded as corresponding to the helix-coil transition of Poly A.

The absorbed heat estimated from the peak area of the DSC curve seen in Figure 1 is about

Table I. Transition temperature $\left(T_{\mathrm{m}}\right)$ and enthalpy $(\Delta H)$ estimated from DSC curves of Poly A solution with different concentrations of $\mathrm{NaCl}$ in acid region

\begin{tabular}{|c|c|c|c|c|c|c|}
\hline \multirow{2}{*}{$\begin{array}{c}\mathrm{NaCl} \\
\text { mol }\end{array}$} & \multicolumn{2}{|c|}{ pH 4.32} & \multicolumn{2}{|c|}{ pH 4.73} & \multicolumn{2}{|c|}{$\mathrm{pH} 5.12$} \\
\hline & $T_{\mathrm{m}}, \mathrm{K}$ & $\begin{array}{c}\Delta H, \mathrm{a} \\
\mathrm{kJ} \mathrm{mol}^{-1}\end{array}$ & $T_{\mathrm{m}}, \mathrm{K}$ & $\underset{\mathrm{kJ} \mathrm{mol}^{-1}}{\Delta H, \mathrm{a}}$ & $T_{\mathrm{m}}, \mathrm{K}$ & $\begin{array}{c}\Delta H, \mathrm{a} \\
\mathrm{kJ} \mathrm{mol}^{-1}\end{array}$ \\
\hline $10^{-5}$ & 364 & $19 \pm 2$ & 344 & $18 \pm 2$ & 330 & $12 \pm 3$ \\
\hline $10^{-4}$ & 364 & $18 \pm 2$ & 345 & $18 \pm 3$ & 330 & $12 \pm 2$ \\
\hline $10^{-3}$ & 363 & $19 \pm 2$ & 345 & $18 \pm 2$ & 330 & $11 \pm 2$ \\
\hline $5 \times 10^{-3}$ & 360 & $17 \pm 4$ & 345 & $15 \pm 3$ & 329 & $10 \pm 2$ \\
\hline $10^{-2}$ & 360 & $12 \pm 3$ & 344 & $13 \pm 2$ & 327 & $10 \pm 2$ \\
\hline $5 \times 10^{-2}$ & 359 & $11 \pm 2$ & 341 & $13 \pm 3$ & 326 & $9 \pm 3$ \\
\hline $10^{-1}$ & 358 & $11 \pm 2$ & 338 & $11 \pm 2$ & 326 & $9 \pm 3$ \\
\hline $5 \times 10^{-1}$ & 357 & $11 \pm 3$ & 339 & $12 \pm 2$ & 318 & $8 \pm 2$ \\
\hline 1.0 & - & - & - & - & 317 & $8 \pm 3$ \\
\hline
\end{tabular}

a The "mol" is a mol of base pair. 
$1.53 \mathrm{~mJ}$, and the transition enthalpy per mol of base pair of nucleotides is about $19 \mathrm{~kJ}$.

The peak temperature $\left(T_{\mathrm{m}}\right)$ and the transition enthalpy $(\Delta H)$ per mol of base pair estimated from the DSC curve of Poly A solution with different $\mathrm{NaCl}$ concentrations at a definite $\mathrm{pH}$ are summarized in Table I.

\section{Transition Temperature}

Plots of $T_{\mathrm{m}}$ of Poly A against the logarithm of salt concentration at a difinite $\mathrm{pH}$ show a contrary sigmoidal curve, as in Figure 2, and approach a definite value in the lower concentration ranges of salt $\left(10^{-5}\right.$ to $\left.10^{-3} \mathrm{~mol} / l\right)$. Values of $T_{\mathrm{m}}$ of Poly $\mathrm{A}$ at infinite dilution of salt concentration at a given $\mathrm{pH}$ are shown in Table II. This $T_{\mathrm{m}}$ depends on $\mathrm{pH}$ only, and increases considerably with decreasing $\mathrm{pH}$; similar results have been reported by other authors. ${ }^{5,6}$

In the moderate concentration ranges of salt,

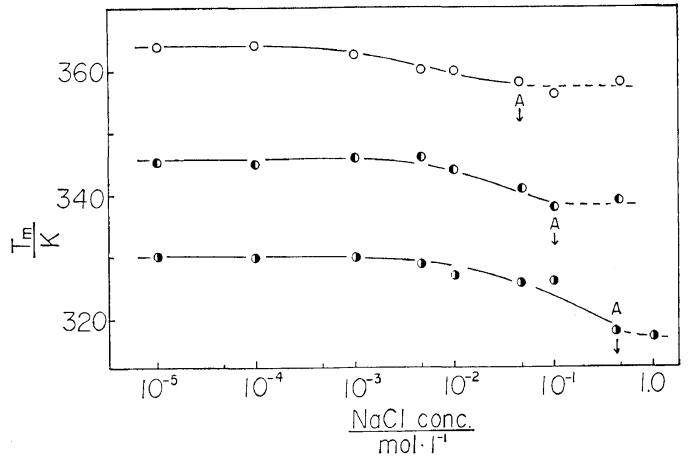

Figure 2. The plots of transition temperature $\left(T_{\mathrm{m}}\right)$ against the logarithm of $\mathrm{NaCl}$ concentration.

$\mathrm{pH}: \bigcirc-4.73 ; \mathrm{D}-4.73 ; \mathrm{C}-5.12$.

A point shows the $\mathrm{NaCl}$ concentration required for aggregates of Poly A solution at room temperature, and the broken lines show $T_{\mathrm{m}}$ of this solution.

Table II. Thermodynamic parameters of Poly A at infinite dilution of $\mathrm{NaCl}$ concentration at various $\mathrm{pH}$ values

\begin{tabular}{cccc}
\hline $\mathrm{pH}$ & $T_{\mathrm{m}}, \mathrm{K}$ & $\begin{array}{c}\Delta H, \mathrm{a} \\
\mathrm{kJ} \mathrm{mol}\end{array}$ & $\begin{array}{c}\Delta S,{ }^{\mathrm{a}} \\
\mathrm{J} \mathrm{deg} \cdot{ }^{-1} \mathrm{~mol}^{-1}\end{array}$ \\
\hline 4.32 & 364 & 19 & 5.2 \\
4.73 & 345 & 18 & 5.2 \\
5.12 & 330 & 12 & 3.6 \\
\hline
\end{tabular}

a The "mol" is a mol of base pair. from $10^{-3}$ to about $5 \times 10^{-2} \mathrm{~mol} / l, T_{\mathrm{m}}$ decreases with increasing salt concentration, in contrast to the result obtained from DNA of double-strand helical structure. This difference may be due to the fact that the electrostatic interstrand interaction between the negatively charged phosphate group and the positively charged adenine contributes significantly to the stabilization of the helix of Poly A, as pointed out by Gabbay. ${ }^{12}$

Poly A solutions with higher concentrations of salt form aggregations at room temperature, and become homogeneous upon raising the temperature. $T_{\mathrm{m}}$ of this Poly A show a definite value in spite of increasing salt concentration, as shown by the broken line in Figure 2. The salt concentration required for formation of aggregates of Poly A solution decreases with decreasing $\mathrm{pH}$, as shown by $\mathrm{A}$ point in Figure 2 . Further study is needed to clarify these results.

\section{Transition Enthalpy}

The plots of transition enthalpy per mol of base pair $(\Delta H)$ against the logarithm of salt concentration, seen in Figure 3, show similar contrary sigmoidal curves to that of $T_{\mathrm{m}} \cdot \Delta H$ at infinite dilution of salt concentration decreases with increasing $\mathrm{pH}$, although $\Delta H$ at $\mathrm{pH} 4.32$ takes a slightly larger value than that at $\mathrm{pH}$ 4.73; the results obtained are summarized in Table II.

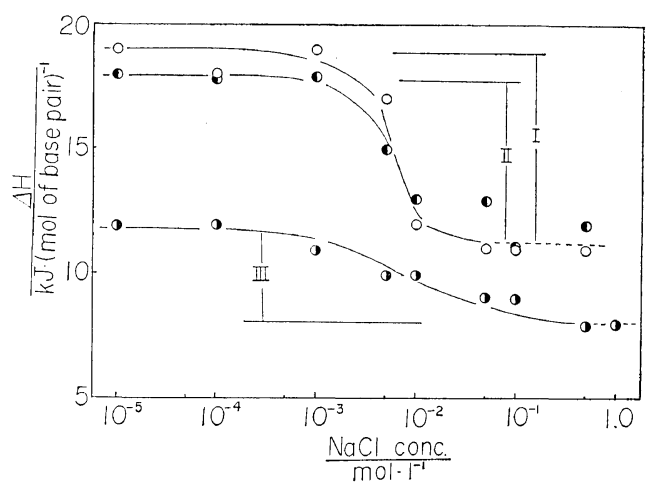

Figure 3. The plots of the transition enthalpy per mol of base pair $(\Delta H)$ against the logarithm of $\mathrm{NaCl}$ concentration.

pH: $\bigcirc-4.32 ; 0-4.73 ; \bigcirc-5.12$.

The difference of enthalpy between lower and higher salt concentrations, I ( $\mathrm{pH} 4.32)$, II ( $\mathrm{pH} 4.73$ )

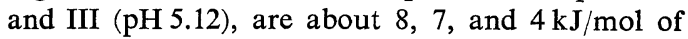
base pair, respectively. 


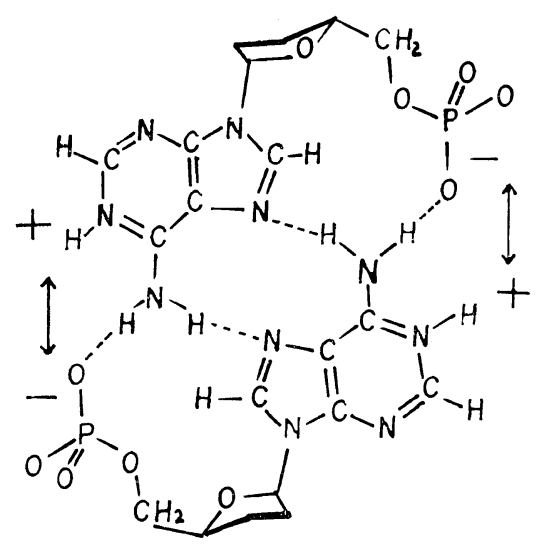

Figure 4. Double-strand molecule of Poly A in acid solution (from ref 15 ).

This dependence may be judged by comparison with results reported by other authors. ${ }^{13-15}$

The calorimetric study of helix formation in Poly $\mathrm{A}^{13}$ has been estimated by means of titration enthalpy; the following enthalpy of reaction was obtained:

$$
\mathrm{N}(\text { coil })+\alpha \mathrm{H}^{+}=\mathrm{NH}^{+} \text {(helix) } \quad \Delta H=-14 \mathrm{~kJ}
$$

where $\mathrm{N}$ represents the nonprotonated nucleotides' residue and $\alpha$ is the fraction of adenine groups protonated at $\mathrm{pH} 4$ in the helical form. The helical form of Poly A is considered to involve the presence of electrostatic interactions between the negatively charged phosphate group and the positively charged adenine group, using the X-ray diffraction studies of Fresco ${ }^{14}$ and Rich, et al., ${ }^{15}$ shown in Figure 4.

In our study, $\alpha$ may differ at a given $\mathrm{pH}$; also, the proportion of $\mathrm{NH}^{+}$may be increased with decreasing $\mathrm{pH}$, from the results of Sturtevant, et al.,$^{13}$ since the number of protons bound per AMP unit decreases with increasing $\mathrm{pH}$ from the titration curve of Poly A. ${ }^{16}$ Accordingly, the important factor for the increase of $\Delta H$ with decreasing $\mathrm{pH}$ may be considered to be that the contribution of the electrostatic interaction energy increases by increasing the fraction of adenine groups protonated with decreasing $\mathrm{pH}$.

In the moderate concentration ranges of salt $\left(10^{-3}\right.$ to $\left.5 \times 10^{-2} \mathrm{~mol}\right), \Delta H$ decreases with increasing salt concentration; this dependence is similar to that of $T_{m}$ described above, and it may be considered that the energy of electrostatic interaction between the negatively charged phosphate group and the positively charged adenine group decreases, since the contribution of electrostatic interaction decreases significantly with increasing salt concentration. The difference of enthalpy shown in Figure 3 may be considered to reflect these contributions of electrostatic interaction and this contribution increases with decreasing $\mathrm{pH}$. But this electrostatic energy cannot be estimated from our study, since we cannot know what fraction of protonated adenine groups is present at a given $\mathrm{pH}$.

According to Table I, the plots of $\Delta H$ against $T_{\mathrm{m}}$ of Poly A with a given salt concentration show a curve in which $\Delta H$ approaches a definite value with increasing $T_{\mathrm{m}}$, as shown in Figure 5. These plots of Poly A with $\mathrm{NaCl}$ concentration of $10^{-2}$ mol have a similar tendency to those with salt concentration of $10^{-5} \mathrm{~mol}$, but the slopes are smaller than is the case with lower salt concentrations. If those curves are roughly regarded as linear, shown by the broken lines in Figure 5, the slopes of the straight lines decrease with increasing salt concentration, corresponding to the heat capacity of the helixcoil transition of Poly A. The slopes of the straight lines at concentration ranges larger than

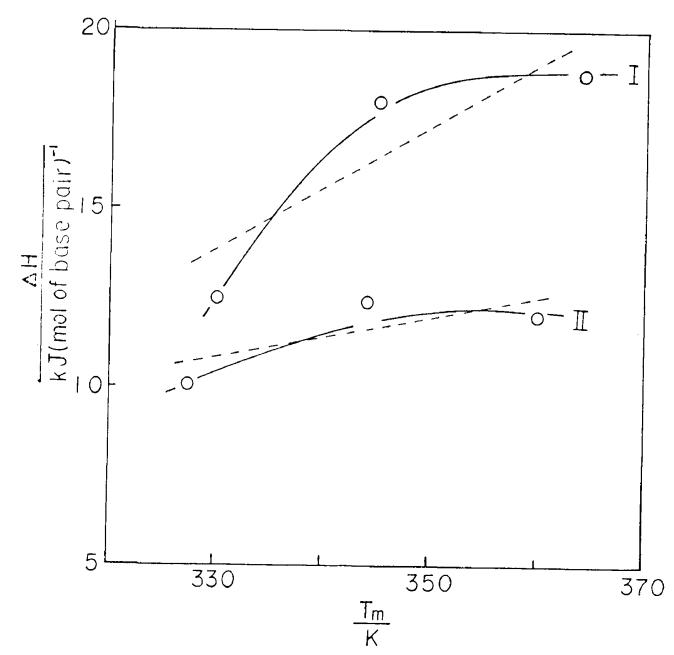

Figure 5. Dependence of the transition enthalpy on transition temperature for Poly $\mathrm{A}$ with a given $\mathrm{NaCl}$ concentration.

$\mathrm{NaCl}$ concn, I-10-5; II-10-2 $\mathrm{mol} / l$. 
about $10^{-2} \mathrm{~mol}$ of salt is smaller than those in the lower concentration ranges of the salt. This difference may be due to the contribution from electrostatic interactions obtained above, and also the different conformations of Poly A between the lower and higher concentration regions of salt may be due to this same contribution.

\section{REFERENCES}

1. J. R. Fresco and P. Doty, J. Amer. Chem. Soc., 79, 3928 (1957).

2. P. O. P. Ts'o, G. K. Helmkamp, and C. Sander, Proc. Nat. Acad. Sci., 48, 686 (1962).

3. K. E. Van Holde, J. Brahms, and A. M. Michelson, J. Mol. Biol., 12, 726 (1965).

4. M. Leng and G. Felsenfeld, ibid., 15, 455 (1966).
5. M. J. Massoulie, Compt. Rend., 260, 5554 (1965).

6. D. M. Holcomb and I. Tinoco, Biopolymers, 3, 121 (1965).

7. J. Marmur and P. Doty, J. Mol. Biol., 5, 109 (1962).

8. C. L. Schildkaut and S. Lifson, Biopolymers, 3, 195 (1965).

9. H. Klump, Th. Ackerman, and E. Neumann, ibid., 7, 423 (1969).

10. C. Stevens and G. Felsenfeld, ibid., 2, 293 (1964).

11. Y. Baba and A. Kagemoto, ibid., 13, 339 (1974).

12. E. J. Gabbay, ibid., 5, 727 (1967).

13. M. A. Rawitscher, P. D. Ross, and J. M. Sturtevant, J. Amer. Chem. Soc., 85, 1915 (1963).

14. J. R. Fresco, J. Mol. Biol., 1, 106 (1959).

15. A. Rich, D. R. Davies, F. H. Crick, and J. D. Watson, ibid., 3, 71 (1961).

16. R. F. Steiner and R. F. Beers, J. Polym. Sci., 30, 17 (1958). 